\title{
Prevalence of Obsessive- Compulsive Disorder in High School Students and Its Interference with the Students' Academic Performance
}

\author{
Emad. Ata Shahrouri
}

\begin{abstract}
Obsessive compulsive disorder (OCD), although being a chronic condition, its impact is mostly linked with psychosocial abilities of students. A total of 60 multi-national high school students completed a series of tests to calculate the severity of OCD symptoms. The tests were based on MOCI index, allowing the researcher to assess the effect of OCD amongst high school students on their academic performance and schoolwork. The last two were identified, in the literature, as the most common of the issues related to OCD observed in teenagers and youngsters. With a majority of the participants reporting minor sy mp toms of OCD in both the observed grades (grade 8 and grade 9 ), it was concluded that OCD is correlated with age. Also, the results from this research were found to be sy nchronous to the past research on student performance under OCD criteria. Given the fluctuating nature of OCD symptoms in school students, studies on OCD treatment need to be fast-tracked and included in standard school regulations to address OCD behavior and effect in students.
\end{abstract}

Index Terms: OCD in students, MOCI, psychometric OCD analy sis, academic performance.

\section{INTRODUCTION}

Obsessive compulsive disorder, also known as OCD, is a condition affecting people in their adolescence or early years of adulthood [27], [5]. According to [2], [3] the definition of ' $O C D$ ' covers both obsession and compulsion (while is either one or both in application) with symptoms changing from person to person. Known to be neurobiological in nature, this condition is amongst the four highly prevalent pediatric psychiatric disorders, observed in the United States of America [4]. An important point to note is the condition that OCD is triggered during childhood which is observed in almost one-third to half of the OCD affected adults [25]. According to the most recent research in this area, the age group including children with the age of 5 and 15 is found to have OCD effect of up to 25 per cent [15]. Students that are affected by the disorder have been found to have a drop in their res pective academic performance [2]. This was the result of the research conducted primarily on adolescents and university students, with lower focus on high school students [18], [1].
Assistant Professor, College of Education, American University in the Emirates, Dubai

\section{LETERITURE REVIEW:}

OCD is associated with obsession and compulsion phenomenon, consuming more time than is required, leading to distress, functionality impairment or anxiety [2]. Characterized with thoughts that are repetitive, distressing and intrusive, obsessions force individuals to cope over the above symptoms with behaviors that are compulsive. Labelled as rather illogical, the compulsive behavior is a repetitive ritual. A good example is the act of washing hands repeatedly. People affected by OCD, as compared to disorders such as unipolar or anxiety disorders, usually face threat even in adulthood, resulting in the form of either unemployment, not getting married or social impairment [21]. In case of children and adults, the clinical presentation of OCD has similar characteristics and affects. Another point to note is the prevalence of OCD across all ethnic groups, which further increases the complexity of treating OCD across different cultures. Obsessions and compulsions have an influence from the cultural habits (to a certain degree). A good example is the compulsion to cleanse in certain ethnic groups. According to the prior research, OCD is found to be a chronic condition that is incons is tent with time [21]; [2]. For example, if a student that has OCD related to obsessive hand washing, may have the compulsion to lower it over several weeks. But the obsession of hand washing re-emerges after that period of time. This type of obsessive behaviors is often linked with stress, as evident by a study of 79 students including adolescents with the OCD disorder that found the linkage [27]. The study concluded that obsessions may change over time, for instance from hand washing to correcting handwriting. This change can be influenced by age too and may become aggres sive in nature. The obsessions and compulsions leading to aggressive nature were identified to be triggered by anxiety linked with brain-based chemical imbalance [30]; [21]. Among the other factors that were found to trigger OCD include viral infections, stress in life, and genetics [25]; [19]; [9]. The table below shares few examples on obsessions as well as compulsions found in school students [See table 1]. 
TABLE 1: OBSESSION \& COMPULSION Obsessions

Aggression - Fearful Impulse
An impulse to hurt self or others
An impulse to steal or break
An impulse to offend someone
Repetition
An impulse to repeat a doubt or question
$\quad$ Example: Repeated doubt if the door is locked.
Contamination
Impulse or fear of being contaminated by everyday activities.
$\quad$ Example: Shaking hand, opening door, etc.
Distress
An impulse to keep things in order-aligned
Arousal of anxiety when finding things out of place or not in order
$\quad$ Compulsions
Repetition in Behavior
An impulse to repeat an activity (triggered by an obsession)
Example: Washing hands repeatedly due to obsession of
becoming contaminated
Example: Counting or Praying

While OCD is termed as a rare disorder, it is found to be prevalent in about 2.5 per cent of the adults (as in USA), with a lifetime prevalence in adolescents and children [16]. Also, it is identified that females have dominance in OCD features over males, as observed in various clinical trials [14]. The onset of OCD is found to trigger during the adolescent age and increase gradually with age [10]. People reaching adulthood with OCD symptoms are affected by impairment that may or may not relate to pursuing steady employment, marital difficulties or general functioning [8]. In the case of adolescents and students identified with OCD symptoms, it is found that they subsequently become socially withdrawn and even conserve energy and time to engage in this compulsive or obsessive behavior [1].

In terms of the treatments available for OCD, there are no treatment established to be successful; however, there are treatments that are successful in controlling the OCD symptoms [30]. One such treatment is the CBT (Cognitive behavior therapy) that is found to be effective [25]; [9]. It applies the process of exposing anxieties and fears in the OCD affected individuals, while instructing them on how to refrain from their compulsions. They are supported with correct beliefs along with critical evaluation of the fears on their future [9].

In case of students, the behaviors of OCD can be misunderstood, which raises the need for teachers to be equipped with the ability to recognize and understand OCD symptoms and tendencies. Intervention can be applied only with increased awareness, while significantly lowering the negative effect of the condition on the learning of students [12]. It is observed that students identified with OCD condition may perform worse in comparison with other students (below the actual potential), leading to less than average academic performance [22]. This effect occurs as OCD symptoms interfere and hinder the concentration ability as well as productivity of students.

OCD effected students display the tendency to have higher disorders related to learning, which may extend to nonverbal learning [19]. This means that such students may lack behind in comparis on with other students, in terms of verbal skills such as spelling, reading and language. They may find it difficult to take up tasks such as mathematics or writing by hand that needs visualattention. Students with OCD can dis play character traits that limit their performance. Such traits include competitiveness, self-criticism, incessant tension/worry, dissatisfaction over performance, controlling, procrastination and increased expectations [22]. These traits need to be carefully noted by the teachers when they start interfering with the functioning of the students with OCD and avoid misunderstanding them. It can even lead to frustration, depression and/or discouragement of the students.

Prior research on OCD and its effect on academic performance of students has been employed for school grade students [13]; [9]; [28]. Various implications were raised based on the above finding; however, the issue was not fully addressed. OCD in case of students made them believe that they read the study material, while they have not [30], while other research [20] highlighted that OCD in students raises the barriers of academic performance Examples include students reworking on their research paper 10 to 15 times to perfect it, or preparing a detailed 'to-do' list that extended their submission by years [16]. A detailed analysis of the literature reflects the fact that OCD in school students and its effect on their academic performance is not examined in detail.

\section{METHODOLOGY}

\section{Setting}

The participants in this research were subjected to convenience sampling from two grades (Grade 8 and Grade 9) classes in a school in Dubai, United Arab Emirates. The classes selected for the high school students were taught by the same teacher in similar educational conditions. The name and location of the school was kept anonymous due to confidentiality purpose.

\section{The Participants}

The total size of each class involved in this research includes of 70 students. The prior academic performance of the participating clas ses was not shared with the researcher, in order to avoid any form of bias during this research. Out of the 70 students, five students were absent during the period in which the data for this research was being collected. volunteer bias is unlikely; this is because the participating students did not have any past knowledge on this form of research. Two students show their unwillingness to participate. A total of 63 questionnaires were distributed amongst the class for data collection, out of which 60 responses were completed with 3 responses eliminated due to incompletion of the questionnaire. For the statistical testing, only the fully completed 60 questionnaires were included in sample. Amongst the 60 
respondents, 36.6 per cent are males and 63.3 are females. The average (mean) age of the sample population was identified as $13.36(S D=4.1$, range $=13$ to 15$)$. The demographic diversity of the sample population was not measured.

\section{PROCEDURE}

The academic performance as sess ment was performed during the mid-term and end-term. This consideration was made to ensure that the participating students didn't exit the research and in turn, cause an effect on the findings. The students were initially briefed about the research and its importance, and were subsequently invited to participate in the research of their free will. The students were pre-informed that that the research will have access to their academic performance, while emphasizing that students can exit the research anytime during the process. It was also made clear to the students that their name, school ID, gender or nationality will not be revealed, and age and gender details will be considered as a whole for statistical evaluation. Also, the above details will not be shared with the class instructor. During the process of data collection, the participating students were given the freedom to ask questions about the research and theirinputs, and to clear any doubts they may have about the process.

\section{Instruments}

Initially, a demographic variable based survey was used to collect information from the participating students. The variables consist of student age, gender, class and identification number. The last variable was later eliminated. The duration of each class was 45 minutes with the maximum and minimum number of classes per day for the two grades was 8 and 9 .

\section{MOCI Inventory}

The MOCI, also known as 'Maudsley Obsessional Compulsive Inventory', was applied to the participants, this is a well-known ins trument widely used to test OCD complaints, and has been applied by various researchers in the past for investigating OCD symptoms among school and university students [8]; [10]. In this research, the MOCI instruction was utilized to as ses s the symptoms and effect of OCD in high school students.

The instrument selected is specifically suitable for group testing, and hence, applied in this research study. It is a simple instrument that consumes a maximum of $15-20$ minutes of the participants' time to complete. The research instrument comprises of 30 questions that are presented in true/false format, the questions are developed in statements so that the students can easily understand and choose the correct response. A few examples of the questions include: (1) 'I repeat some things again and again', (2) 'I am very careful when I do my activities, but often feel that it is not right'. An overall index was provided by the MOCI, considering 30 as high and 1 as low, and developing the scoring by the number of responses towards the high and low. In prior researches, the MOCI has been identified to have a good consistency, validity as well as stability [11].

\section{Assessing Academic Performance}

The final grades of the participating students were assessed by the class teacher, and later used by the researcher to match with the student ID numbers collected. However, the ID numbers were later dismis sed before conducting the statistical tests with the academic grades.

\section{QUESTIONS AND RESULTS}

The questions proposed in this study were as follow:

$\mathbf{1}^{\text {st }}$ Question: Is there any significant differences between the two classes (grade 8 and grade 9) in OCD complaints in their respective scores of MOCI?

In ordered to examine the differences between the two classes, an independent t-test performed on the data, the incorporation of these tests was needed to identify the difference in OCD complaints within the two classes. The $8^{\text {th }}$ grade students $(n=30$, Mean $=43.966)$ and $9^{\text {th }}$ grade students $(n=30$, Mean $=44.233)$. The calculated t-value (-3.125) is significant (.000) with DF 58. This result reflects significant differences in their respective scores of MOCI in favour to grade 9. Table 2 illus trate the Group Comparis on for OCD of grade 8 and 9.

T ABLE II GROUP COMPARISON FOR OCD OF GRADE 8 AND 9

\begin{tabular}{|ll|r|c|r|c|}
\hline & GRADE & \multicolumn{1}{|c|}{$\mathrm{N}$} & Mean & Std. Deviation & $\begin{array}{c}\text { Std. Error } \\
\text { Mean }\end{array}$ \\
\hline TOTAL1 & grade 8 & 30 & 43.9667 & .18257 & .03333 \\
& grdae 9 & 30 & 44.2333 & .43018 & .07854 \\
\hline
\end{tabular}

2nd Question: Is there any correlation between academic performance of students and the OCD complaint?

To answer this question, correlation-based observation between the academic performance of students and the OCD complaint was conducted. A high score of MOCI in students with lower academic performance was registered $(\mathrm{p}<0.05)$. It was found that students with lower symptoms of OCD have dis played better academic performance. Moreover, the score of MOCI was found to have no significance with the number of study hours of the students.

3rd Question: Is the score of MOCI can be applied to predict academic performance of the students?

The third test conducted using the sample data was linear regression. The aimwas to identify if the score of MOCI can be applied to predict academic performance of the students. As supported by the correlational analys is above, a modest level of MOCI scores was identified with significance with academic performance $\mathrm{p}<0.05 ; \mathrm{R} 2=0.099$ ).

TABLE 3 LINEAR REGRESSION MODEL FOR ACADEMIC PREDICTION

\begin{tabular}{|c|c|c|}
\hline \multicolumn{3}{|c|}{ Model Summary } \\
\hline Model & $\mathrm{R}$ & R Square \\
\hline 1 & $.315 \mathrm{a}$ & .099 \\
\hline \multicolumn{3}{|c|}{ a. Predictors: (Constant), GRADE } \\
VI. DISCUSSION
\end{tabular}

In this research, a detailed relationship analysis was conducted between OCD and academic performance of student at high school level as sample. In support to our hypothesis, a poor academic performance of school students was associated with OCD based behavior, with symptoms such as too much 
attention to detail, lack of confidence in executing a task, repeating activities and failing to complete activities. High school students that displayed lower symptoms of OCD were found to have a better academic performance over students with OCD symptoms in both the grades. These results are synchronous with the prior findings on OCD in school students [12]; [23]; [30].

High school students with lower study hours were found to have reported compulsive behavior and obsessive thoughts. This can be attributed to 'perfectionism', leading to symptoms of OCD [4]. These are found to interfere with the academic performance of university students [16], as well as with adolescents [1]. In our research, it can also be due to the reason that few students feel satisfaction in the amount of efforts they have put in their respective academic performance. Or, they may have felt overwhelmed due to the large amount of academic activities in the schoolcurriculum that made them overlook their academic performance. The results identified in this research can also be attributed due to the students engaging in behavior of OCD, thereby affecting their performance due to these symptoms.

\section{COMPARATIVE ANALYSIS}

The symptoms of Obses sive compulsive behavior were found to be significantly higher in grade 9 students over grade 8 . This finding was slightly expected in line with the findings from previous research [12], that conclude OCD behavior may increase with age. While the age gap between the students from the two grades can be overlooked, however, the validity of this finding cannot be exempted. The average of grade 9 score of MOCI is almost similar to that of grade 8 (see table 2). This can be due to the fact that the two classes comprise of a mixed nationalities and gender in almost similar proportions. Also, the competitive study environment may have triggered the feeling in the students to be perfect and achieve higher scores leading to display of symptoms of OCD. Another point to note is the significance found between OCD symptoms and academic performance of grade 9 to be higher in MOCI scores too, with the respective students earning lower academic performance.

In the higher clas s, the OCD complaints were identified not be significantly high in students with more age over the others. This can be attributed to the high school level of both grade 8 and 9, learning under similar educational environment. A difference may have been observed if the comparison was made between middle schoolstudents and high school students, with more clear age differences and academic learning syllabus.

\section{LIMIT ATIONS}

One major factor that governed this research was the small sample size. The negative effect of this is restricting the statistical testing in order to examine relationship between the variables. However, it cannot be accounted for as the standard deviation was found to be adequate for review. Another point is the low findings on OCD as only $18 \%$ of the participants reported symptoms of OCD, through the MOCI scores. However, as this is not a clinical or sub-clinical examination, in future, researcher may streamline this research on OCD in school students thereby advancing in OCD understanding. Another limitation of this research was the lack of ethnic inclusion in the data collection, which thereby restrict detailing the findings with respect to age and ethnic groups, and how each factor affected academic performance.

Cultural factors have a certain level of influence on a student's study habits and academic learning [24]. A study conducted by [14] examined obsessive and compulsive behavior in different ethnic groups in university students and found significant differences. Also, few authors [8] used a larger sample size with students from diverse ethnic groups that help achieve identification of differences in OCD complaints across the ethnic groups. The research should have used different methods of academic performance review apart from the grade point. However, this decision was to take straight forward approach and examine the grades to reach a clear analysis. Though the outcome did reveal substantial significance between MOCI scores and academic performance of students, the grades were restricted to one class. In future, inclusion of multiple classes can aid researchers in examining any diversity in the relationship and if certain classes tend to increase OCD characteristics in school students, tending to have visible effect on academic performance.

\section{IMPLICATIONS}

In the school, educational system, educators and teachers should pay attention towards any sign of obsession or compulsive behavior amongst school students and report any identification to initiate corrective action [5]. They should be made aware of the potential effect of OCD on school students and their adulthood, as OCD is a condition that can persist even after schooling.

There are various variations in OCD based behavior in the academic field at school level, which as reported by [9]; [5] may extend to college level. It can emerge in terms of (1) inability or difficulty to take note, (2) repeating an activity such as reading a line several times, (3) paying detailed attention and rearranging things again and again (example: academic supplies). OCD behavior can be found is adolescents too, however, it is difficult to identify and control. With respect to school students, it can be identified and hence controlled so that the student may benefit. As indicated by [17], cognitive performance of students may have an affect due to obsessive intrusions that distract the students thus affecting their overall academic performance. Also, it affects their ability to make decisions or prioritizing activities/tasks leading to absenteeis $m$ and tardiness [12].

To identify any pattern or features of obsession or compulsion in students, a procedure comprising of MOCI, similar to that applied by other researchers for high school students and college students, can be applied [21]. The high school students can be screened in order to identify the symptoms through the self-reporting system. This can be achieved either by (1) taking up a confidential screening (one to one) with the students, (2) conducting question and answer sessions thereby allowing students to ask and clear their doubts on what comes under OCD and how to control it, (3) using a MOCI test to access academic difficulty due to OCD. 
For students with obsessive-compulsive behavior, it is very important to have assessment as they may be exposed to embarrassment or criticism [23]. This affect can force them to conceal their behavior or doubts on how to control their obsession-compulsions, while not seeking any assistance as required. It is vital to raise encouragement amongst such school students to avail assistance so that they do not lose out on academic opportunities. Also, it is crucial as not doing so can lead to underestimation of OCD in school students.

\section{INTERVENTION}

Obsessive compulsive behavior in students can be presumed to be conscientious or something that relates to the personal qualities of the student affecting his/her academic performance. Though this is widely exaggerated, in reality, it is a problem that seeks timely and effective intervention and support [30]. Students identified with clear OCD issues are recommended treatment; however, this is delivered in the form of psycho-pharmacological and cognitive behavioral intervention (in combination) [23]. These interventions are delivered on school campus allowing them the needed support to control and overcome their obsessions and compulsions. These otherwise may have led to isolation or ridicule from fellow students [37]. The most important step is to make the students aware of such condition and how it is affecting their personal and academic life. It should be made a standard service by including in the school services, while the school body entering partnership with healthcare bodies to provide the needed support.

\section{CONCLUSION}

Obsessive compulsive Disorder (OCD) is a psychiatric condition that is debilitating in nature and can extend to adulthood in school children. The symptoms of this condition may initiate during the school age or as early as adolescence. It can subsequently extend its affect not only on the personal health of the student but also, the academic performance. Factors such as delay in identification or unwillingness of parents to accept the symptoms may further delay appropriate diagnosis of this condition. Upon diagnosis, the student children can be treated for the condition through therapy or with medication in combination thereby bringing in positive effect. However, leaving OCD untreated puts the school students at risk of further deepening the condition.

\section{REFERENCES}

[1] Adams, G. B, Waas, G. A., March, J. S., and Smith, C. M., (1994). Obsessive-compulsive disorder in children and adolescents. School psychology Quarterly, 9, $274-294$. https://doi.org/10.1037/h0088290

[2] APA. (2000). Diagnostic \& Statistical Manual of Mental Disorders. 4 Ed. Washington, DC: Author.

[3] American Psychological Association. (2000). Diagnostic and statistical manual of mental disorders (4th ed., text rev.). Washington, DC: Author.

[4] Adams, G. B., \& Burke, R. B. (1999). Children and adolescents with Obsessive-Compulsive Disorder. Childhood Education, 76(1), 2-7. https://doi.org/10.1080/00094056.1999.10522061
[5] Adams, G. B. (2004). Identifying, assessing, and treating Obsessive-Compulsive Disorder in school-aged children: The role of school personnel. Teaching Exceptional Children, 37(2), 46-53. https://doi.org/10.1177/004005990403700206

[6] Brown, A, Di Nardo, A, Lehman, L, and Campbell, A, (2001). Reliability of DSM-IV anxiety and mood disorders: implications for the classification of emotional disorders. Journal of Abnormal Psychology, 111, pp. 49-58. https://doi.org/10.1037/0021-843X.110.1.49

[7] Calvocoressi, M, et al. (1999). Family accommodation of obsessive compulsive symptoms: instrument development and assessment of family behavior. Journal of Nervous and Mental Disease, 187, pp. 636-642. https://doi.org/10.1097/00005053-199910000-00008

[8] Cameron, C. (2007). Obsessive-compulsive disorder in children and adolescents. Journal of Psychiatric and Mental Health Nursing, 14(7), pp.696-704.

https://doi.org/10.1111/j.1365-2850.2007.01162.x

[9] Cameron, D. L., \& Region, C. H. (2007). Obsessive-Compulsive Disorder in children and adolescents. Journal of Psychiatric and Mental Health Nursing, 14, 696-704. https://doi.org/10.1111/j.1365-2850.2007.01162.x

[10] Durdle, H. (2008). A Meta-Analysis Examining the Relations among Pathological Gambling, Obsessive-Compulsive Disorder, and Obsessive-Compulsive Traits. Psychological Reports, 103(6), p.485 https://doi.org/10.2466/pr0.103.6.485-498.

[11] Fischer, J., and Corcoran, K. (1994). Measures for clinical practice a source book. (2 ed). New York: The free press.

[12] Freeman, J. B., et al. (2007). Cognitive behavioral treatment for young children with Obsessive-Compulsive Disorder. Biological Psychiatry, 61, 337-343. https://doi.org/10.1016/j.biopsych.2006.12.015

[13] Frost, R. O., Sher, K. J., and Geen, T. (1986). Psychotherapy and personality characteristics of nonclinical compulsive checkers. Behaviour Research and Therapy, 24, 133 - 143. https://doi.org/10.1016/0005-7967(86)90084-7

[14] Hanstede, M., Gidron, Y. and Nyklíček, I. (2008). The Effects of a Mindfulness Intervention on Obsessive-Compulsive Symptoms in a Non-Clinical Student Population. The Journal of Nervous and Mental Disease, 196(10), pp.776-779. https://doi.org/10.1097/NMD.0b013e31818786b8

[15] Heyman, I., Fombonne, E., Simmons, H., Ford, T., Meltzer, H., \& Goodman, R (2001). Prevalence of Obsessive-Compulsive disorder in the British nationwide survey of child mental health. The British Journal of Psychiatry, 179, 324-329. https://doi.org/10.1192/bjp.179.4.324

[16] Hughes, C and Campbell, L. (1991), Character Style and career and educational concerns in college students, Journal of college student psychotherapy, 5, $23-45$ https://doi.org/10.1300/J035v05n04_03

[17] Maki, S., et al. (1994). Do clinical checkers exhibit deficits in cognitive control? Behaviour Research \& Therapy. 32(1), p.183-192. https://doi.org/10.1016/0005-7967(94)90111-2

[18] National Institute of Mental Health. (2008). P.A.N.D.A.S. Retrieved May 08, 2016, from http://intramural.nimh.nih.gov/pdn/web.htm

[19] Oldham, J. M., and Morris, L. B. (1995), New personality self-portrait. New York: Bantam.

[20] Paige, L. Z. (2007). Obsessive-Compulsive disorder. Principal Leadership, 8(1), 12-15.

[21] Parker, Z., \& Stewart, E. (1994). School consultation and the management of Obsessive-Compulsive personality in the classroom. Adolescence, 29, 563-574.

[22] Penn, J. V., \& Leonard, H. L. (2001). Diagnosis and treatment in children and adolescents. In M. T. Pato \& J. Zohar (Eds.), Current 
treatments of Obsessive-Compulsive disorder (pp. 109-132).

Washington, DC: American Psychiatric Publishing

[23] Piacentini, J., Bergman, R., Keller, M. and McCracken, J. (2003).

Functional Impairment in Children and Adolescents with Obsessive-Compulsive Disorder. Journal of Child and Adolescent Psychopharmacology, 13(supplement 1), pp.61-69. https://doi.org/10.1089/104454603322126359

[24] Piacentini, J., \& Bergman, R. L. (2000). Obsessive-Compulsive disorder in children. The Psychiatric Clinics of North America, 23, 519-533. https://doi.org/10.1016/S0193-953X(05)70178-7

[25] Rasmussen, S. A., \& Eisen, J. L. (1990). Epidemiology of obsessive-compulsive disorder. Journal of Clinical Psychiatry, 53(Suppl.), 10-13, Discussion 14.

[26] Rettew, D. C., Swedo, S. E., Leonard, H. L., Lenane, M. C., \& Rapoport, J. L. (1992). Obsessions and compulsions across time in 79 children and adolescents with Obsessive-Compulsive disorder. Journal of the American Academy of Child and Adolescent Psychiatry, 31, 1050-1056 https://doi.org/10.1097/00004583-199211000-00009

[27] Simonds, L., Thorpe, S. and Elliott, S. (2000). The obsessive compulsive inventory: psychometric properties in a nonclinical student sample. Behavioural and Cognitive Psychotherapy, 28(2), pp.153-159.

[28] Vanin, J. R. (1990). Obsessive-compulsive disorder: Suffering in silence. College Health, 39, $47-48$. https://doi.org/10.1080/07448481.1990.9936211

[29] Wagner, A. P. (2002). What to do when your child has Obsessive-Compulsive Disorder: Strategies and solutions. Rochester, NY: Lighthouse Press.

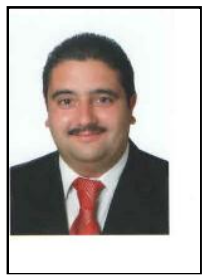

First Author Dr. Emad. A. Shahrouri holds a Ph.D. in Educational Psychology, and a Master's degree in Measurement and Evaluation from the Department of Educational Psychology in the University of Jordan.

He has taught in several GCC universities, worked as an Academic Advising Center Director, and has presented several training courses and specialized workshops on continuous assessment, teaching and learning, and SPSS for statistical analysis. Dr. Shahrouri has special interest in research concerning teaching and learning, as well as assessment and evaluation. $\mathrm{He}$ is both an Assistant Professor in the College of Education and a Counselor in the Guidance and Counseling Center, and has been teaching courses such as General Psychology and Introduction to Social Sciences since September 2013. 